University of East London Institutional Repository: http://roar.uel.ac.uk

This paper is made available online in accordance with publisher policies. Please scroll down to view the document itself. Please refer to the repository record for this item and our policy information available from the repository home page for further information.

To see the final version of this paper please visit the publisher's website.

Access to the published version may require a subscription.

Author(s): Rustin, Michael

Article Title: Learning from the Victoria Climbié Inquiry

Year of publication: 2004

Citation: Rustin, M. (2004) 'Learning from the Victoria Climbié Inquiry', Journal of Social Work Practice, 18(1) 9-18.

Link to published version: http://dx.doi.org/10.1080/0265053032000183679

DOI: $10.1080 / 0265053032000183679$

Publisher statement:

http://www.tandf.co.uk/journals/copyright.asp

Information on how to cite items within roar@uel:

http://www.uel.ac.uk/roar/openaccess.htm\#Citing 
(Published in Journal of Social Work Practice, 18, 1, pp 9-18, (March 2004)

\section{Learning from the Victoria Climbié Inquiry}

\section{Michael Rustin}

The effectiveness of services responsible for the care of children in Britain has on many occasions over recent years been brought to public attention by disastrous failures to protect children in need. These have often been cases which have led to the death of an individual child - these include among others Maria Colwell (1973), Jasmine Beckford (1984), Tyra Henry (1984), Kimberley Carlile (1986) and Victoria Climbié in February 2000. Another event given huge public attention was the multiple diagnosis of child sexual abuse and consequent removal of children into care in Cleveland in1987. Such cases have on several occasions been investigated by quasi-judicial Inquiries, whose published Reports have then become central documents in public discussion and in government decision-making. Since these inquiries have invariably found that poor or negligent professional practice was in part responsible for the fate of the children concerned, they have led to a great deal of public criticism of the relevant services, and in particular of social work. It is clear that the reputation and self-esteem of the social work profession has been gravely affected by these highly-publicised events and by the Inquiries and published Reports have so often followed them.

The Victoria Climbié Inquiry is thus the latest in a long line. Its Report ${ }^{1}$ has two very considerable merits. The first is that its author, Lord Laming, has responded with deep seriousness to the terrible fate of Victoria Climbie herself. No-one can read the Report and not be moved by its descriptions of Victoria's last days of captivity and virtual torture, confined to a bath in the most pitiful conditions. It is clear that the persistence and thoroughness of the Inquiry were animated throughout by the memory of what had happened to

\footnotetext{
${ }^{1}$ The Victoria Climbié Inquiry: Report of an Inquiry by Lord Laming. Cmd 5730 HMSO. January 2003. Available on-line at www.victoria-climbie-inquiry.org.uk
} 
this child, and by a determination to find out how this had come and how such an event could be prevented in the future. The Report's second merit is its rigorous investigation of what had happened to bring this catastrophe about. It sets out in meticulous detail the sequence of events which took place as the case came to the attention, or inattention, of various public services, and describes the discussions, communications, and actions which followed at each point. We learn a great deal about who did what in relation to this case, and about how, when, and where, their various actions and inactions took place.

As the Report makes clear, and as has been widely noted, each of the major public services which had responsibility for the child performed exceedingly badly, social services, hospitals, and the police all failing to respond appropriately to the needs of the child. Doctors, police officers, and social workers, repeatedly failed to take actions that they should have taken, according to recognised procedures, and in implementation of their own prior decisions. Any one of several such actions might have saved Victoria's life. The Report's many Recommendations have largely been formulated in response to the analysis of these defects of practice. It identifies many necessary improvements in the location of professional responsibilities, in inter-agency communication, in operational procedures, and in record keeping and information systems, which if implemented would, it may be assumed, make such catastrophes less likely to occur in the future.

However while the Report is thorough and acute in its ascribing of particular responsibilities - often individual ones - for the tragic misconduct of the case, there are some broader explanatory questions which it scarcely addresses. There is in the first place the problem of what can be reasonably inferred from a particular case such as this, taking place as it did in the sphere of responsibility of several agencies in inner London boroughs, for the condition of child protection services across the country. How representative of prevailing practice is the poor standard of practice which was manifested in 
this one case? How can valid recommendations for improvements in services be made without evidence not only of what happened in this instance, but concerning the standard of practice which prevails more generally? No such broader evidence is adduced by the Report, nor does the further investigation which might produce such evidence figure as one of its numerous recommendations.

\section{Typical and Untypical Practices}

The question of how representative or otherwise this case is of broader practices has two dimensions. One concerns the individual case itself. Did Victoria suffer because of qualities particular to herself and to the adults in whose care she was, and if so, in what ways? The Report does indicate some case-specific factors which were probably relevant to its outcome. It refers for example to the difficulties of joint working between social services and police brought about by ethnic dimensions - for example, the reported suspicion by social workers of police insensitivity's and prejudices towards black people, and some consequent police reluctance work with social services staff. The fact that Marie-Therese Kouao, Victoria's great-aunt and foster-carer, had recently come to London from Paris, was mainly Frenchspeaking, and originally came like Victoria from the Ivory Coast, was another significant factor, impeding the services in establishing contact and communication with her. Another aspect of the family's origins and situation were not, however, made much of in the Inquiry Report. This is the evident ambivalence of some of the services concerned, and indeed of the wider society at this time, to migrants, even legal migrants such as Kouao and Victoria who came to Britain from France, a fellow-member of the European Union. Migrants like this seeking housing and other support from the welfare services have hardly been made welcome in the United Kingdom in these years. Kouao, as the Report refers to her, was perceived to be seeking housing support from the local authority, and there was suspicion that she was manipulative in her dealings with its officers for this reason. Although public responsibility for the well-being of a child was accepted, at least to a 
degree, it seems possible that some of the stigma and hostility being more broadly attached to refugees at this time was a factor in the misrecognition of and official indifference to the situation of this family. At one point Kouao and Victoria were believed by social workers, on no good evidence, to have returned to France. It seems clear that had they indeed done so many of those concerned with the case would have been relieved that their responsibility had been removed. The Inquiry Report does not explore the possibility that animosity towards refugees in this period may have been a contributing factor to the neglect of Victoria's needs, or indeed that other children who are in this situation might now for the same reasons be at risk.

A second question about the case, so far as its representative status is concerned, relates to its particular geographical and administrative location. One might in principle wonder whether a single case is ever a valid indicator of the general quality of a particular local service. But in this case the extent of the failures of the various services engaged does perhaps give good reason to be concerned about their prevailing standard. The failures that were uncovered did not seem to be wholly contingent, for example the result of weaknesses of individual professionals, such as are bound to occur in any organisation. Lord Laming comments sharply on the failure of the Social Services managers to accept appropriate responsibility for what had taken place under their authority, thus suggesting a deeper-rooted problem. And while he commends the senior police witnesses for their candour and acceptance of ultimate responsibility, he also notes generic weakness of the units responsible for child protection in two inner London police services. But even if one accepts that this Inquiry into a single case - 'a single case study', if one thinks of it by analogy with research procedures - can throw light on the larger context of the case, this does not settle the question of what is the relevant context is. Can this case be taken to reveal service deficiencies merely in the four London boroughs investigated (Haringey, Ealing, Brent and Enfield were all involved with the case to some degree), in inner London more widely, in deprived inner city areas across Britain, or of child care services throughout the nation? On the basis of what evidence is this crucial question 
to be answered? Surely deciding on the scope and extent of the service failures which have been identified is absolutely fundamental to drawing any valid conclusions from them. How can useful recommendations to improve policy and practice be made from a single case, if there are no grounds for knowing how representative of normal practice the single case is? Indeed, if one hopes to devise policies and procedures that can be expected to be effective, one needs understanding of how good practice is achieved at least as much as anatomies of failure.

\section{Explanations of Failure}

By what methods should one try to explain serious failures in organisational and professional practice, such as occurred in the Victoria Climbié case? One approach is a predominantly judicial one. This is primarily concerned to establish the responsibility and guilt of individuals, and it adapts the method of the law in order to establish not legal guilt, but professional, bureaucratic or more broadly human fault or failure. This was the model underlying the procedures of this Inquiry, like others of its kind, which were usually conducted by lawyers. ${ }^{2}$ Since this approach is primarily concerned with assigning responsibilities to individuals, it is largely uninterested in broader social scientific or 'systemic' kinds of explanation, and is poorly adapted to investigating causes or dimensions of this kind. The quasi-judicial form of investigation can cope readily with questions of who did what, when, how and where. It can perhaps address the question of 'why' in seeking evidence of an individual's motivation or state of mind when in a particular situation. Such broader dimensions may be brought out by way of mitigation, as occasionally in this Report when individuals are admitted to have been overloaded in their work, or under-trained for their responsibilities. But conceptions such that a problem may be generated by a systemic institutional failure, or by a maladaptative culture, or by pervasive anxiety, ${ }^{3}$ are unlikely to be addressed

\footnotetext{
${ }^{2}$ The Victoria Climbié Inquiry is an exception - Lord Laming is an eminent social worker, and a former Chief Inspector of Social Services.

${ }^{3}$ Margaret Rustin, in a paper ('Conceptual Analysis of Critical Moments in Victoria's Life') given at a Tavistock Clinic Conference on these issues on October $10^{\text {th }} 2003$ explored the unconscious anxieties which undermined the capacity of the professional network to take in
} 
within a quasi- judicial framework like that of the Inquiry's. Where the primary task is to attribute individual responsibilities, which is what courts and their analogues normally do, explanations which invoke such contextual or environmental factors may even seem like unjustified pleas of mitigation or exoneration by individuals who have failed in their responsibilities. ${ }^{4}$

Where the prime objective is to locate individual responsibilities, reflective thought may also be put aside by the pressing need for individuals to defend and rationalise their actions. The legal representation which witnesses to the Inquiry had available to them may be, effective in ensuring a measure of justice and fairness, but it is not conducive to open-minded reflection, in which the admission of misjudgement or negligence may be the precondition for understanding what was in the minds of participants, and why they acted as they did. I don't think we really learn from this Report how those involved with the case themselves interpret, understand, and evaluate what happened in its course. But surely at some level their testimony and reflections must be vital to a full understanding of the situation.

If the larger system in which practitioners found themselves is indeed seriously malfunctioning, then we are unlikely to avoid such disasters in future if the larger malfunctions, as well as the failings of individual practitioners, are not addressed. If, for example, inadequate levels of training, insufficient or poor professional supervision, a management remote from the primary work it is supposedly managing, lack of qualified staff, and poor relationships between different agencies and professions, are all factors leading to inadequate individual work, improvement is unlikely to take unless such problems are addressed. 'Responsibility', in the real sense, lies here, in these determining conditions, and with those who shape them, and not only

the facts of the case, and thus to respond to Victoria's needs. This paper can be obtained on request from MRustin@tavi-nhs.port.org

${ }^{4}$ Appointed inspectors have tended to displace independent social scientists as the main providers of evidence on which to base government policy in recent years. The starting-point of this trend was the denunciation of the 'establishment' of academic education researchers by 
with the 'street-level bureaucrats' who administer these systems on an individual basis. Indeed, one can say that a form of Inquiry that only seriously examines practitioner-failures, and gives little attention to the broader preconditions of these, is in effect shrugging off responsibilities that really belong to the larger society and its organisation, which should not be largely attributed to its front-line workers.

What struck me in reading the Inquiry Report is how many occasions there were in which any one individual among many could have made a difference to Victoria's fate, just by taking the responsibility on to themselves. No-one ever seems to felt strongly enough that the evidence of harm and risk to this child was such that something must be done to investigate it further. Doctors, police officers, and social workers, even nurses, were all at different moments in a position to have insisted on relevant action being taken. If any of them had, it seems likely that someone else involved would have accepted the necessity for this and given their support. The Climbié case did not actually disappear from official sight - formal procedures ensured that it remained more-or-less on the agenda of several agencies for many months but no-one took it up with the urgency it called for. It reminds one of the notorious Kitty Genovese incident which took place in the United States in 1964 where a crowd of neighbours around a tenement courtyard saw and heard a murder taking place, over a period of half an hour, and no no-one actually did anything to help, even by phoning the police. ${ }^{5}$ What researchers have reported induces citizens to intervene in such cases is on the one hand a sense of self-confidence in individuals, and on the other a sense of having a latent relationship to other bystanders, such that they can be presumed to share some common feelings and standards. In the Victoria Climbié case, it seems both that the relevant professional self-confidence was widely lacking, and that different professionals were relating to one another as

the Thatcher government, and its installation of the Ofsted regime under Chris Woodhead as its preferred source of information and advice on schooling.

${ }^{5}$ See Rosenthal, A.M. Thirty-Eight Witnesses: The Kitty Genovese Case. Berkeley : University of California Press, 1999. 
virtual strangers, as if they were members of alien organisations, not as members of a multi-disciplinary professional community sharing a common commitment. The arguments that went on about whether child protection committee meetings should take place in one agency's premises, or another, were symptomatic of this lack of a common identification. The professional culture around this case seemed to be in a state of fragmentation and lassitude. The informal culture of an organisation or network is often as influential as its formal rules in shaping its day-to-day activities. Indeed sometimes formal regulations are little more than a skeleton whose animation depends on much interaction that is unspecified or improvised, as normal life proceeds. The rules, like most job specifications, are necessary, but they are rarely sufficient to make things work.

\section{Lord Laming's Recommendations}

The Inquiry Report makes no less than 108 recommendations to improve child protection services and practice. The first General set of these is for 'Structural Change'. The Report proposes a new administrative framework for these services, through the establishment of a ministerial Children and Families Board, and a National Agency for Children and Families to report to it. It is recommended that local authorities should replicate this structure at their territorial level, with a Committee for Members for Children and Families and a Management Board for Services for Children and Families. One of the tasks of the new National Agency should be to undertake or oversee the conduct of serious case reviews. Thus not only is a significant reorganisation of government proposed on the basis of a single serious case-review, but such 'hard cases' are in future to be accorded similar centrality. No justification is given in the Report of this approach to policy-making. But soon after the Report was published, the government announced that it proposed to bring about major changes in the child protection system, in the light of the Report's recommendations. Since it is unlikely that governments really do make major decisions on such ad hoc grounds, it seems more likely that the 
Climbié case and the Inquiry that it gave rise to has provided a populist rationalisation for what government for other reasons considered to be a desirable development.

The remaining 91 Recommendations are directed in turn to the major agencies with responsibility for child protection services - Social care, Health care, and the Police. These recommendations are largely for improvements in operating practices and procedures. They require that records be kept in all cases, that appropriately qualified professionals take appropriate decisions, that investigations are promptly undertaken about children where deliberate harm is suspected, and are then implemented, that information systems are improved $^{6}$, that greater priority is given to child protection services, that specialist training is given, that services become properly co-ordinated, etc..

These recommendations seem reasonable ones, though it is not clear which of them represent proposed changes in existing procedures, and which of them merely re-state what is already prescribed. Can it be, for example, that social services child and family intake teams are not already supposed to have experience in working with children, and to have received appropriate training? Or that when social services staff discover that a child they are assessing is not attending school they are not already expected to inform the education authorities of this fact? What Lord Laming appears to have done in formulating many of his Recommendations is to note what was not done adequately in the Climbié case, and then recommend that what evidently should have been done then should be a standard procedure in future. But it does not seem sufficient to advocate changes in procedure without detailed reference to those which are already in use. Such an approach could indeed encourage mindless compliance to specific rules, (the ticking of endless new

\footnotetext{
${ }^{6}$ Improvement in IT systems surely could make a significant difference in these cases, given the history of failed, unreadable and mislaid communications that bedevilled the case. Perhaps this is something that the new agencies proposed by Lord Laming will investigate on a systematic basis. Whether such improvements should include the National Data Base for Children that the Report recommended is another matter.
} 
boxes) rather than unified attention to the whole system of responsibilities and practices in which any set of procedures must be located. ${ }^{7}$

\section{Bureaucratic and Holistic Models of Service Provision}

The Inquiry Report does make its own connection between the behaviour of individuals and the larger institutional structure to which they belong, and by which they are employed. Its recommendations make clear where this connection is held to lie. The intervening dimension on which it relies to organise and connect up individual behaviours is that of rules and procedures, compliance with which is to be enforced by a hierarchical management structure. This is an essentially bureaucratic model of organisation, even though it is conceded that within this rule-bound structure individual professionals are going to be required to exercise discretion and judgement.

One of the largest issues in current debates about the desired 'improvements' in public services now revolves around the question of how adequate such a bureaucratised model of service-delivery and its management is. Are there dimensions of the process of delivering services that it leaves out, or marginalises, that need to be present if improvement is to be achieved? Is it likely, for example, that child care services would be sufficiently improved if Lord Laming's Recommendations were followed? Or indeed is it likely that they will be followed in practice if the broader dimensions of the situation that led to the Victoria Climbié tragedy are not first understood?

\footnotetext{
${ }^{7}$ The Government, in the Secretary of State's immediate response to the publication of the Report on January $28^{\text {th }} 2003$, annnounced in fact that it proposed to rationalise the 1500 pages of guidance to which the 1989 Children Act and its successor Acts had given rise into a unified document of only one tenth the length, and it also (re-) announced the extension of qualifying social work training from two to three years, a long overdue development. Whilst pursuing the standard agenda of holding responsible individuals to account and increased inspections, it thus also addressed some of the more holistic issues. Its considered position is set out in the Green Paper 'Every Child Matters' which is now out for consultation. This document can be accessed on the Web at http://www.dfes.gov.uk/everychildmatters/
} 
What might these dimensions be? This is the topic for a separate investigation, some of the materials for which exist in some of the valuable evidence submitted to the Inquiry (it is freely accessible on-line) which is however barely referred to in the body of the Report. (The reports of the seminars to which those invited to give evidence contributed are also disappointing ${ }^{8}$ ). But among these dimensions is certainly the quality of professional training and supervision available to staff, in all the services scrutinised by the Inquiry but especially in social services and the police. Demands by the Report that all social workers should be qualified for working with children are largely pieties, given both the shortage of qualified social workers in London, and also the inadequate quality of training that many qualified social workers have received, and the perfunctory nature of much that is offered by way of continuing professional development. The Report notes that social services managers appeared to distance themselves from responsibility for what their front-line workers were doing, but chooses not to note that this might now be a systemic deficiency, brought about by the weak and repeatedly undermined professional identity of social workers. In strong professions, such as medicine, or most academic disciplines, those in management positions retain their commitment to a community of values shared at all levels. In weak professions, like social work, there are continuing pressures for senior staff to redefine their role in generic 'management' terms, weakening their grasp of and influence over the professional culture of the knowledge-base and professional culture of their field.

It is necessary for professionals working in child care, as in all other professions primarily concerned with human relationships, to remain open to experience, to retain a desire to understand, and on the basis of such understanding make assessments. ${ }^{9}$ It is a notable feature of the Climbie case that no-one ever seems ever to have been very interested to understand

\footnotetext{
${ }^{8}$ The seminar reports make a few gestures in a holistic direction, for example in 17.70 , on the need for a 'learning culture'. But these do not offset the proceduralist emphasis of the whole Report.
} 
either Victoria, or her great-aunt, Marie-Therese Kouao, even though such a desire to understand could have been of fundamental value. Kouao is viewed in the Report in the light of the cruel outcome of her care of Victoria, as though the end of the case so far as her behaviour was concerned always lay in its beginning. No-one seems to have thought to find out why the child was in such evident trouble, and whether Kouao might have been offered any help in looking after her. The Report is silent on what was believed to have happened to bring about Victoria's cruel captivity - what seems to have been a descent into near-madness of her carers. The child's bedwetting seems have been a visible symptom of these difficulties, as of course were her evident injuries. One wonders if a conversation with Kouao intended not from the first to seek a case for prosecution, but to ascertain if a relationship of some trust might have been established with her, could have averted this disaster. After all, one question one might ask is what would have to have happened for the child to be brought to the hospital not when she was already dying, but earlier when there would still have been hope for her.

A further question concerns what one might broadly call the problems of scarcity in social care, the fact that there is simply not time and resources to do everything equally well in difficult conditions, especially in areas of high social stress, such as that in which the Climbié case occurred. The Report seeks to impose obligations on services, including hospitals, to give the highest priority to suspected cases of deliberate injury to children. But in reality, is it not reasonable for medical services to determine priorities by the evident risk to life of their patients, not by the origins of injuries or illness that might lead to death? Any change in the order of priority given to one activity, necessarily reduces the priority to be given to another. What particular displacement of concerns did the Inquiry Report have in mind when it came to its recommendations? Plainly, none, since its frame of reference was one in which insistence on priorities in one part of a service does not require that

\footnotetext{
${ }^{9}$ Andrew Cooper, Rachael Hetherington and Ilan Katz's short book Risk Factor, The Making the child protection system work by Andrew Cooper, Rachael Hetherington, and Ilan Katz (Demos 2003) proposes ways in which such space for reflection might be provided.
} 
anyone first thinks about the implications of this for any other. This is what I mean by referring to the absence of any systemic or holistic dimension in the Report's analysis of the problems.

It seems to be that this Report replicates the deficiencies not only of a certain dominant style of public service management, specifying objectives and insisting on compliance at the expense of recognition of the complexity of tasks and the capabilities necessary to cope with them, but also of the inspection regimes which have grown up to audit and supervise them. An Inquiry like this has the form and function of an Extraordinary Inspection, and is liable to be as mechanistic and unimaginative in its response to the problems revealed as many current public service inspections now are. ${ }^{10}$

\section{Ways Forward}

Some of the Evidence submitted to the Inquiry suggests some alternative lines of approach to the problems exposed by the Inquiry. For example, Professor Colin Pritchard's evidence, from the University of Southampton, draws attention to the improvement in child safety that has taken place in the UK over recent decades, and to the evidence of who, from the evidence, the different perpetrators of injury to children are most liable to be, (He draws attention to psychiatric risks, and points out that this was one dimension to which professionals might have been more attentive in their interactions with Kouao. $)^{11} \mathrm{He}$ also reports on a project which has integrated school, health and social services provision in Dorset which indicates that a nonstigmatising, preventive approach can produce much better and more costeffective outcomes than current fragmented methods which focus on intervention at later stages of neglect and harm. ${ }^{12}$ Sir William Utting, like Lord Laming a former Chief Inspector of Services, expressed his scepticism about

\footnotetext{
${ }^{10}$ On this see M.J. Rustin 'Rethinking Audit and Inspection', paper given at a Tavistock Clinic Policy Seminar on October 17 2003. (Available on request from author).

${ }^{11}$ Margaret Rustin's paper, cited above, also explores the state of mind of Victoria and her great aunt, as far as the evidence allows.

${ }^{12}$ In fact, school-based prevention systems are an important element in the Government's 'Every Child Matters' Green Paper proposals, referred to above.
} 
organisational restructuring as a remedy, and drew attention to the fundamental importance of high levels of professional training and capability. Julia Ross, Director of Social Services and Chief Executive of the Primary Care Trust in Barking and Dagenham, argued that ' it is not the structures, but the cultures, the people, and the systems failures that need addressing.' One can see a distinction in much of the evidence submitted to the Inquiry between those who subscribe to proceduralist and bureaucratic approaches to service-improvement and those who favour more systemic and holistic approaches. It is a great advance in the methodology of such Inquiries (it was also a merit of the Hutton Inquiry) that they now lead to the placing in the public domain of such a valuable body of evidence and argument. ${ }^{13}$

The setting up of new overseeing Agencies, such as Lord Laming proposes for children and family services, does not in itself prescribe the methods by which they will work. There is an opportunity for these new agencies to address the problems of child and family services in a more holistic and openminded way than is done through most of this Report. They could, for example, commission research studies to ascertain by what methods effective child and family services deliver their good results, and what differentiates successful forms of practice from unsuccessful ones. They could explore the needs of training, and the optimal forms of management, for these services, in an open-minded spirit. They could ask for a review of the current systems of audit and inspection of these services, which after all failed to detect or remedy the gross malfunctions which led to the crisis revealed by the Victoria Climbié case.

There is an opportunity for the new structures to review the services accountable to them in a fundamental way. This may not have been what Lord Laming had in mind when he recommended that they be established,

\footnotetext{
${ }^{13}$ The submissions of on-line evidence to the Climbié Inquiry would be made more accessible by a clearer list of contents and an index.
} 
but it could be an outcome of his Report's recommendations which would be of lasting value.

Comments can be addressed to m.j.rustin@uel.ac.uk 